\title{
Modeling the decline of labor-sharing in the semi-desert region of Chile
}

\author{
Andres Baeza $^{1,2}$ (1) $\cdot$ Marco A. Janssen ${ }^{2}$
}

Received: 25 March 2017 / Accepted: 23 October 2017 /Published online: 22 November 2017

(C) The Author(s) 2017. This article is an open access publication

\begin{abstract}
The rapid environmental changes currently underway in many dry regions of the world, and the deep uncertainty about their consequences, underscore a critical challenge for sustainability: how to maintain cooperation that ensures the provision of natural resources when the benefits of cooperating are variable, sometimes uncertain, and often limited. In this work, we present the case of a group of rural communities in a semi-desert region of Chile, where cooperation in the form of labor-sharing has helped maintain higher agriculture yields, group cohesion, and identity. Today, these communities face the challenge of adapting to recurrent droughts, extreme rainfall, and desertification. We formulated an agent-based model to investigate the consequences of regional climate changes on the fate of these labor-exchange institutions. The model, implemented in the framework of prospect theory, simulates the economic decisions of households to engage, or not, in labor-sharing agreements under different scenarios of water supply, water variability, and socio-environmental risk. Results show that the number of fulfilled labor-sharing agreements is reduced by water scarcity
\end{abstract}

Editor:Diana Sietz.

Electronic supplementary material The online version of this article (https://doi.org/10.1007/s10113-017-1243-0) contains supplementary material, which is available to authorized users.

Andres Baeza

andres.baeza@gmail.com

Marco A. Janssen

Marco.Janssen@asu.edu

1 National Socio-Environmental Synthesis Center, University of Maryland, College Park, MD, USA

2 Present address: School of Sustainability, Arizona State University, Wrigley Hall, 800 Cady Mall, Tempe, AZ 85281, USA and environmental variability. More importantly, defections that involve non-fulfillment of these agreements are more likely to emerge at the intermediate level of environmental variability and water supply stress. These results underscore the need for environmental policy instruments that consider the effects of regional climate changes on the social dynamics of these communities.

Keywords Cooperation $\cdot$ Rainfall $\cdot$ Drought $\cdot$ Agent-based model $\cdot$ Labor-sharing $\cdot$ Risk

\section{Introduction}

Cooperative behavior among multiple actors of a society is critical to ensure the provision of resources and other ecosystem services (Daily et al. 2000; Anderies 2015). Given the inherent complexity of socio-ecological systems, however, decisions to build and maintain trustworthy cooperative institutions are often made under deep uncertainty about the potential costs and benefits associated with these agreements (Herman et al. 2014). A critical question is therefore how to generate and maintain sustainable cooperative behavior for managing natural resources, when the long-term benefits of engaging in those enterprises are not well defined, often limited, and under high levels of risk and uncertainty (Janssen et al. 2007). This work contributes to this body of literature by simulating the decisions to cooperate made by households in agricultural communities of the semi-desert region of Northern Chile. In these communities, informal cooperation institutions in the form of labor-sharing agreements have emerged, in an environment that today is forced by climatic uncertainty, long-lasting droughts, and extreme rainfall events. We are particularly interested in understanding how 
the regional climatic changes currently underway in this semidesert region influenced these labor-sharing agreements.

Labor-sharing refers to the exchange of labor between individuals or households without relying on money (Suehara 2006; Debebe 2010). This is a common practice among many peasant societies around the world, and it is an important strategy for reducing marginal and wage-related costs, as well as for increasing household income and labor efficiency (Gilligan 2004; Gerichhausen et al. 2009). From a social perspective, labor-sharing helps communities maintain social bonds and collective identity while enhancing cohesion (Downey 2010). While the evolutionary origin of these institutions seems to be related to kinship proximity (Hames 1987), their structure - that is, the number of meaningful and successful cooperative interactions between members - is shaped by multiple direct and indirect reciprocal interactions that over time shape group identity and social capital (Suehara 2006; Waring 2006). It is possible then that over long temporal scales, these agreements may be influenced by changes in the biophysical environment that in turn shape many of the short-term economic decisions.

For rural communities living in dry environments, the combination of long dry seasons and extreme variability in rainfall regarding the water supply results in risky economic conditions due to the uncertainties around water supply (Reynolds et al. 2007). These precarious prospects of future outcomes cause farmers to undertake multiple strategies to cope with uncertainty, aimed at maintaining economic viability over longer periods of time (McAllister et al. 2006). If, therefore, social interactions are modulated by changes in the socioecological environment, how do resource scarcity, its variability over time, and the inherent socio-ecological uncertainty at the moment of decisions influence the stability of these cooperative labor-sharing agreements?

To provide insight into this question, we developed and analyzed an agent-based model inspired by the laborsharing documented in the rural communities of Northern Chile. Our aim is to understand how labor-sharing agreements have been influenced by the extreme variability and scarcity in water supply these communities face, and how uncertainty about this supply prospect influences the fulfillment of these agreements. These communities are located in a transitional climatic zone, where regional changes in atmosphere and oceanic patterns of the subtropical Pacific region have influenced regional rainfall trends, causing the Chilean side of the Andes to confront longer inter-annual periods of drought in summer and more extreme rainfall events in winter (Minetti et al. 2003; Souvignet et al. 2010). These communities face the challenge of adapting to these environmental and climate changes by varying their economic decisions over time (Alexander 2008; Salas et al. 2012).
The agents in the model are households of a community. Each household makes decisions as to whether to engage in the production of a rain-fed crop, whose productivity depends on the availability of water that is assumed to be variable and unknown. Under this climatic uncertainty, households must decide if they will engage in informal agreements to share labor with other households. The decisions to share labor (cooperate) are made on the bases trust and reputation of the households. Trust is defined as the probability that a household will cooperate based on previous direct interactions, and reputation is defined as the average trust of a household in the community based on the interactions with other households (Mui et al. 2002; Janssen 2008).

The decision-making process of the households is implemented using the framework of prospect theory (Kahneman and Tversky 1979). Prospect theory (PT) introduces important aspects from cognitive psychology into more "traditional" econometric models, including considerations of risk perception and risk attitude, which cause it to deviate from standard expected utility approaches (Wakker 2010). It describes in mathematical terms how people make decisions, not just by choosing among alternative options that involve probabilistic events but also by assuming that people make behavioral choices that are biased by the context, social or physical, to avoid losses or to seek gains (Hastie and Dawes 2010). The theory has been used to understand human decisions in multiple arenas to represent uncertain and ambiguous alternatives, such as international relationships (Goldgeier and Tetlock 2001), financial risk management (Fiegenbaum 1990), and insurance markets (Sydnor 2010), and it has been applied recently to problems related to natural resource management in variable environments (Podestá et al. 2009). We use PT to represent the risk behavior and perception of gains and losses when households decide to establish cooperation agreements and make final decisions that involve environmental ambiguity and social risk based on trust and reputation.

In the next section, we briefly summarize the institutional arrangements of the agricultural communities of the north of Chile, the type of environmental variability to which these communities are exposed, and the strategies that have emerged over the past 50 years to cope with and adapt to these environmental conditions. We then describe the structure of the agent-based model and the numerical experiments constructed to test the effects of water scarcity and water variability on the cooperative decisions of the community in conditions of social and climatic risk. We end the paper by discussing our results in the context of empirical research needed to test the influence of socioenvironmental risk, along with the potential implications of the results for moving forward with environmental policies to halt the environmental degradation affecting the semi-desert region of Chile. 
Agricultural communities in the semi-desert regions of Chile

In the semi-desert territory of Chile, between the Atacama Desert and the fertile, wine-producing valleys of central Chile, 178 agricultural communities occupy more than $10,000 \mathrm{~km}^{2}$ of three administrative regions. Each of these communities is composed of a group of households with individual rights to use community land for individual productive purposes (Ministerio de Bienes Nacionales 2017). The most common purpose the community assigns to the land is the production of crops, of which the most commonly planted is wheat. Common land within the community is designated and managed by the community members themselves. On this common land, many households engage in pastoral activities for the production of cheese, milk, meat, and leather. Besides agriculture and livestock activities, members of the communities also engage in off-farm activities, which mostly take the form of work in mining, construction, or large-scale agriculture.

These kinship-based communities can be traced back to the 1800 s, when the rights to the land were passed down to the descendants of Spanish colonists (Silva et al. 1978). Since 1932, the Chilean government has recognized them as selfgoverning units, which means that each of them has a governance structure to manage their natural resources. Today, each community is governed internally by institutions that define the rights to common land, designating resting areas and animal quotas for livestock, and determining the needs and priorities of the community regarding investment in public goods, such as irrigation systems. Social organizations are also present, overseeing cultural traditions like group harvesting and cheese production, as well as organizing sporting events and social gatherings (Rocha Pérez 2006).

The environment in which these agricultural communities are located is defined as a semi-desert and with Mediterranean climate, with dry summers and a short rainy season in winter. The land is mostly classified as "el secano," which is defined by its low productivity, high susceptibility to erosion, and low carrying capacity for livestock. Most of the households in these communities do not have access to surface water for irrigation (Hearne and Donoso 2014). In consequence, the economic return is highly variable and strongly dependent on rainfall and ground water, forcing the farmers to rely on fast-cash rain-fed crops such as wheat. However, the production of these crops is uncertain and dependent on the amount of water the rainy season will bring.

This strong dependency on water is critical for understanding the decisions and strategies of these communities. Before the rainy season, agreements to share labor are designed to help each other with activities related to agriculture, such as preparation of the land, seeding, or planting, and the expectation for help continues until the end of the agricultural season with the harvesting of the production (Alexander 2008). However, during the rainy season before the harvest, a household must decide whether to continue investing time in the community or diversify its portfolio of options given the current water situation it faces. The most common of these options is for one or two members of the household to leave the community temporarily to work off-farm, seasonal jobs, most often in the wine and liquor production industry, mining, and construction. Another diversification option is to take the animals and rent land from other communities or private landowners in areas with better conditions for animals to feed and survive (Alexander 2008). In both situations, water availability determines the need for households to choose between staying in the community and leaving for better opportunities.

The decision to leave the community would imply, in principle, a reduction of the amount of time individuals would have to fulfill their labor-sharing agreements, at the time in the season when the help would be most critically needed for harvesting the crops. Because the most common crop planted is wheat, the harvest season is short and has to be carried out at a specific point in time before the grains dry out. Because of this, labor during harvesting is intensive, and the help from others is essential for completing the work on time. Moreover, labor-sharing during this time generates higher yields that otherwise would not be possible if the household members work by themselves. Not receiving this type of help can be extremely detrimental. However, when households rely heavily on others for maintaining production without reciprocating a fair amount of time contributing to the agricultural needs of others, they are seen as "free riders," which thereby reduces their trustworthiness and the overall reputation of the household (Alexander 2008).

\section{The model}

\section{The community}

A community is defined as a group of $N$ households of farmers producing agriculture in a water-driven environment. Each year, households must decide to either set an agreement with other households to share labor to increase the production of both farms or leave the community and use the time to work in paying (wages) jobs. These agreements, however, are made under conditions of uncertainty about how much water the season will bring, and they must be validated after the households have more information regarding the availability of water (Fig. 1).

\section{Agriculture production and utility function}

When a household decides to stay in the community, it will produce and harvest a crop. We assume that the "annual" 
Fig. 1 Flow diagram of households' decisions. The decision to cooperate and share labor is made in two steps: before and after the rainy season. Before the rainy season, a decision is made under climatic uncertainty as to whether to set an agreement. After the rainy season, a second decision is made as to whether to fulfill the agreement, and it is made under uncertainty as to whether or not the other family will cooperate. Circles represent the environmental and social uncertainties

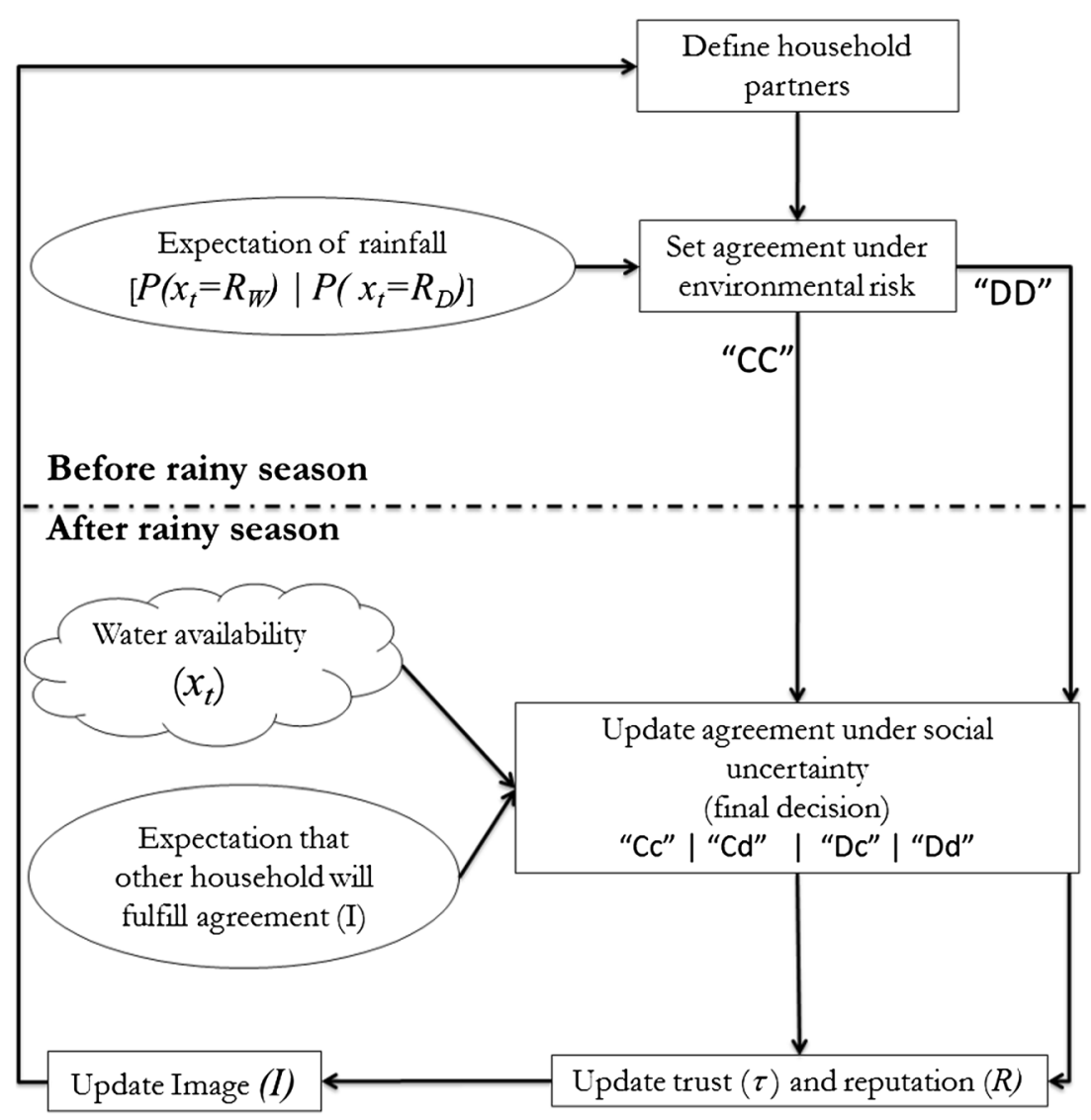

harvested crop $H_{i, t}$ is influenced by the amount of land $A_{i}$; the total labor for production, $L_{i, H}$; and a seasonal (variable) climatic, rainfall effect $x_{t}$, such that,

$H_{i, t}=\varphi x_{t} A_{i} L_{i, H}$,

where $\varphi$ is the factor of cooperation. This is a parameter that is greater than 1 when both households decide to engage in labor-sharing, and $\varphi=1$ if not. This is the benefit of cooperation.The total labor for production for household $i$, $L_{i, H}$, is defined as

$L_{i, H}=L_{i}-L_{i, C}+L_{j, C}-L_{i, W}$,

where $L_{i}$ is the total labor of a household $i, L_{i, W}$ is the time a household spends working outside the farm in paying jobs, and $L_{i, C}$ is the labor provided by household $i$ to household $j$ and $L_{j, C}$ the labor received from household $j$ to household $i$. We assumed that in an agreement setting, households share the same amount of time; therefore, $L_{i, C}$ and $L_{j, C}$ cancel each other out in a fulfilled agreement as both families help each other. However, this symmetry breaks down if one of the families does not fulfill the agreement (see Table 1). The utility of household $i$ at time $t, U_{i, t}$, is defined as the sum of the gains obtained from the private farm $\left(H_{i, t}\right)$ and from off-farm wages, $W$, such that

$U_{i, t}=H_{i, t}+W L_{i, W}$

where $W$ is the off-farm wage per unit of labor invested by household $i$ in working off-farm, $L_{i, W}$.

Table 1 Possible outcomes for household $i$ to decide if engaging or not in a labor-sharing agreement, given the possible decisions of household $j$

Household $j \quad$ c: Stay in the community, work on farm, and share labor $\quad$ d: Divide time working on farm and off farm, but do not engage in Household $i \quad$ with household $i$ labor-sharing

C: Stay in the community, work on farm, and share labor with household $j$

$$
\begin{array}{ll}
U_{i t}^{C c}=\varphi x_{t} A_{i} L_{i} & U_{i, t}^{C d}=x_{t} A_{i}\left(L_{i}-L_{i, C}\right) \\
U_{i, t}^{D c}=\varphi x_{t} A_{i}\left(L_{i}+L_{j, C}-L_{i, W}\right)+w L_{i, W} & U_{i, t}^{D d}=x_{t} A_{i}\left(L_{i}-L_{i, W}\right)+w L_{i, W}
\end{array}
$$

D: Divide time working on farm and off farm, but do not engage in labor-sharing 


\section{Modeling variability of water}

Equation 1 includes variable $x_{t}$ to represent inter-seasonal changes in yield related to water availability. For the sake of the argument, the model assumes that the community would experience only good (wet) or bad (dry) years of water availability, and the difference between a good rainy year, $R_{W}$, and a bad dry year, $R_{D}$, is represented by $R_{v a r}$, such that

$x_{t}=\left\{\begin{array}{l}1+R_{\text {var }}=R_{W} \\ 1-R_{\text {var }}=R_{D} .\end{array}\right.$

Thus, the larger the value of parameter $R_{\text {var }}$, the bigger the difference is between a drought and a highly productive year. Therefore, water variability in this work is defined as the magnitude of the difference between a good and a bad year.

We also considered that these climatic events could be correlated in time. By following Caswell (2001), we define the probability of having a bad or a good spell, conditional on the last rainfall event, using the following expressions:

$P\left(x_{t}=R_{W} \mid x_{t-1}=R_{D}\right)=1-\rho-P\left(x_{t-1}=R_{D}\right)(1-\rho)$

and

$P\left(x_{t}=R_{D} \mid x_{t-1}=R_{W}\right)=P\left(x_{t-1}=R_{D}\right)(1-\rho)$,

where $P\left(x_{t}=R_{D}\right)$ is the unconditional probability of having a bad, dry year, and $\rho$ is the temporal correlation between rainfall events. When $\rho=0$, these conditional probabilities become the unconditional probabilities $P\left(x_{t}=R_{W}\right)=1-P\left(x_{t}=R_{D}\right)$.

Using these expressions and setting parameters $R_{v a r}$ and $\rho$ to particular values, we generated random realizations of $x_{t}$. Scenarios with higher probability of a good year represent environments with low levels of hydric stress, and scenarios with higher values for parameter $R_{v a r}$ are environments with high variability of water between years.

\section{Prospect theory}

Before explaining how the labor-sharing agreements and the final decisions are made, we need to explain the main assumptions of prospect theory (PT) that will mathematically define the choices (prospects) under environmental and social risk. The main assumption of prospect theory is that people evaluate options based on their perception of loss and gain; their attitude toward risk; and, finally, the probability of those options. What differentiates a loss from a gain is a threshold or, more precisely, a reference point that is a reflection of people's expectations or beliefs about past outcomes or the outcomes of others. In addition, PT assumes people have an attitude toward risky behavior that weighs gains and losses differently. It is important to note that in PT risk, attitude can represent different types of behavior, such as risk aversion, relentlessness, or indifference to the perceived risk (Wakker 2010). Moreover, in PT, people weigh events differently based on the probability that such events will happen. Commonly, people underestimate events that are less commonly observed, such as extreme storms that happen once every 100 years. Less often, people overestimate events occurring more frequently. Placing the model in the framework of PT allows for the evaluation of the importance that risk attitude may have on the social structure of these communities when confronted with a variable and unpredictable environment.

In the next two sections, we define the decision-making process of households in these communities using the mathematic formulation of PT for both the agreements made before the rainy season and the final decisions. We compare the results obtained with PT against a modified model that does not consider risk attitude and instead evaluates the agreements and final decisions using absolute quantities rather than a relative measure of gain and losses. This modified model is called the "Expected Utility" (EU) formulation. The modifications to the model along with the simulation results are presented in the Online resources document (Expected Utility formulation). A graphical comparison of the results obtained under $\mathrm{PT}$ and EU is also presented in fig. 3.

\section{Agreement under environmental risk}

At the beginning of the planting season, before the rains have fallen, each household must decide if it will engage in exchanging labor with other households in the community (Fig. 1). Households are paired with probability proportional to the trust both households have in each other and their reputation based on previous interactions with other households. After households have been paired, they mutually evaluate two possibilities: first, they can stay in the community, work on their farms, and share labor. This decision is one that leads to both staying in the community, " $C C$ ", and it can happen during a good year with abundant water, in which case the utility obtained is labeled $U_{W}^{C C}$. Alternatively, they can cooperate in a bad year with low water, in which case the utility is $U_{D}^{C C}$. The second option is that they can mutually decide not to share labor and instead work on their own farms and offfarm. This decision would give $U_{W}^{D D}$ in conditions of abundant water, with " $D D$ " as the agreement to not cooperate, and $U_{D}^{D D}$ in the case of a dry year. The following equations provide the four possible prospects to evaluate:

$U_{W, t}^{C C}=\varphi R_{W}\left(A_{i} L_{i}+A_{j} L_{j}\right)$

$U_{D, t}^{C C}=\varphi R_{D}\left(A_{i} L_{i}+A_{j} L_{j}\right) L$ 


$$
\begin{aligned}
U_{W, t}^{D D}= & R_{W}\left(A_{i}\left(L_{i}-L_{w}\right)+A_{j}\left(L_{j}-L_{j, w}\right)\right) \\
& +\left(W L_{i, W}+W L_{j, W}\right) \\
U_{D, t}^{D D}= & R_{D}\left(A_{i}\left(L_{i}-L_{w}\right)+A_{j}\left(L_{j}-L_{j, w}\right)\right) \\
& +\left(W L_{i, W}+W L_{j, W}\right),
\end{aligned}
$$

In general terms $U_{y, t}^{g}$ with $g=\{C C, D D\}$, and $y=\{W, D\}$. The valuation of these four prospects by a household incorporates considerations of the subjective perception of gains and losses with respect to a reference point. Here, we assume that this reference point for family $i, U_{i, t}^{r e f}$, is defined as the average of the utility obtained in the five previous time-steps, or

$U_{i, t}^{r e f}=\frac{1}{\Delta t} \sum_{t=1}^{t-\Delta t} U_{i, t}$.

A difference measure between the prospect and a reference point for an agreement is constructed using

$\Delta U_{y, t}^{g}=U_{y, t}^{g}-\left(U_{i, t}^{r e f}+U_{j, t}^{r e f}\right)$.

A positive outcome of $\Delta U$ is perceived as a gain. Using this subjective evaluation of gains (and losses when $\Delta U_{y, t}^{g}<0$ ), a value function $v$ is constructed using the probabilities of these prospects:

$V(U, \pi, g)=\Omega\left(\pi_{W}\right) v\left(\Delta U_{W, t}^{g}\right)+\Omega\left(\pi_{D}\right)^{*} v\left(\Delta U_{D, t}^{g}\right)$.

The form of function $v$ is such that it considers the risk behavior of the farmers to evaluate the gains and losses $U_{y, t}^{g}$. We used the formulation from Wakker (2010):

$$
v\left(\Delta U_{y, t}^{g}\right)=\lambda\left|\Delta U_{y, t}^{g}\right|^{a} \cdot(12) .
$$

Using this formulation and specific parameter values, two types of communities were specified: a community composed of gain-seeking farmers and another with loss-averse farmers. Gain-seeking farmers do not pay much attention to losses and outweigh gains. In such case, the value function $v$ is parameterized using

$\left\{\begin{array}{c}\lambda=1, a>1 \text { if } \Delta U_{y, t}^{g} \geq 0 \\ -1<\lambda<0, a=1 \text { if } \Delta U_{y, t}^{g}<0\end{array}\right.$.

In the other case, loss-averse farmers outweigh losses and pay little attention to gains. In such cases, function $v$ is parameterized with

$$
\left\{\begin{array}{l}
\lambda=1,0<a<1 \text { if } \Delta U_{y, t}^{g} \geq 0 \\
\lambda<-1, \quad a=1 \text { if } \Delta U_{y, t}^{g}<0
\end{array} .\right.
$$

The perception of risk is also subjective with regard to the evaluation of these possibilities. That is, farmers do not rely on the objective probability of an event. This subjectivity can be captured by a parametric form of a weighting function proposed by Kahneman and Tversky (1979):

$\Omega(\pi)=\frac{\pi^{c}}{\left(\pi^{c}+(1-\pi)^{c}\right)^{\frac{1}{c}}}$,

where $\pi$ is the probability of the next rainfall event $\left(R_{W}\right.$ or $\left.R_{D}\right)$. Given the assumption of environmental risk, households calculate the prospects using $\pi=P\left(x_{t}=R_{W} \mid x_{t}=R_{D}\right)$ (Eqs. 4 and $5)$.

\section{Final decision under social risk}

As stated in the introduction, the agreements made by the households in a community are informal, that is, there is no legal bond that ensures fulfillment. Therefore, we assume that as the season proceeds, the households can update an agreement according to the environmental information obtained (Fig. 1). This is implemented by assuming that the final decision is made with farmers knowing the true environmental outcome, i.e., $x_{t}$. However, the calculation of the expected gains or losses is now made under the uncertainty that the other household will fulfill its agreement (Fig. 1). Table 1 shows the possible outcomes of each decision from the point of view of one household, given the possible final decisions of another household.The expected utility of household $i$ under the risky prospect that the other household will fulfill the agreement is calculated using

$V_{i}{ }^{C}=\Omega\left(I_{i, j, t}\right) v\left(\Delta U_{i, t}{ }^{C c}\right)+\Omega\left(1-I_{i, j, t}\right) v\left(\Delta U_{i, t}{ }^{C d}\right)$

and

$V_{i}^{D}=\Omega\left(I_{i, j, t}\right) v\left(\Delta U_{i, t}^{D c}\right)+\Omega\left(1-I_{i, j, t}\right) v\left(\Delta U_{i, t}^{D d}\right)$

Function $v$ is the value function evaluated for the individual reference point of household $i$ for each one of the four possible final decisions, $\Delta U_{i, t}{ }^{f}$, with $f=\{C c, C d, D c, D d\} . I_{i, j, t}$ is the expectation from household $i$ that household $j$ will fulfill the agreement, and it is represented by the image of the household, a function of the trust household $i$ has in household $j$, and the reputation of household $j$ (see below). This is the social risk associated with the final decision. Thus, when $V_{i}^{C}>V_{i}^{D}$, the household will stay in the community, work on its own land, and engage in sharing labor.

\section{Trust, reputation, and expectation of cooperative behavior}

Trust and reputation influence the image each household has from each other, and this image defines the expectation that a given household will fulfill an agreement. Formally, the image that household $i$ has of household $j$ is defined by 
$I_{i, j, t}=\varepsilon \tau_{i, j, t}+(1-\varepsilon) R_{j, t}$,

where $\tau_{i, j, t}$ is the level of trust household $i$ has in household $j$ at time $t$, and $R_{j, t}$ is the reputation of household $j$. Parameter $\varepsilon$ represents the importance households give to direct (trust) and indirect (reputation) interactions. The level of trust household $i$ has in household $j$ is

$\tau_{i, j, t+1}=(1-\mu) \tau_{i, j, t}+\mu S_{i, j}$,

where $\mu$ is a parameter that defines the memory of the household. $S_{i, j}$ is the score of the interaction of household $i$ with household $j$. The trust a household has in others changes over time according to the outcome of this interaction between the households. The following score sheet was used to define the outcome of each interaction:

$S_{i, j}= \begin{cases}0 & \text { if } g=C C \text { and } f \text { of } j=d \\ \frac{1}{3} & \text { if } g=D D \text { and } f \text { of } j=d \\ \frac{2}{3} & \text { if } g=D D \text { and } f \text { of } j=c \\ 1 & \text { if } g=C C \text { and } f \text { of } j=c .\end{cases}$

where $S_{i, j}$ represents the score that household $i$ assigns to household $j$ after a single interaction, by comparing the final decision made by household $j$ against the agreement made between the two before the rainfall season.

Thus, a household would score better when both the initial agreement and the final decision were to stay and share labor, and the score would be the lowest when the agreement was to share labor "CC", but the final decision was to leave the community, "d". A household does not rely solely on direct trustworthy interactions to define an image; it also relies on the interactions of others. We define this as the "reputation" of a household. Reputation is defined as the average trust other households have in a household, such that

$R_{j, t}=\left(\frac{1}{(N-1)} \sum_{k=1}^{k=N} \tau_{k, j, t .} \quad \forall k \in C: k \neq j\right)$,

where $\mathrm{C}$ is the set of households in a community of size $N$.

\section{Numerical experiments}

We simulated the model using different levels of water abundance and environmental variation. We constructed scenarios of water abundance by varying $P\left(x_{t}=R_{W}\right)$, which ranges from 0.1 to 0.8 . We also constructed scenarios with different levels of variability between dry and rainy years, from no variability, $R_{v a r}=0$, to a highly variable environment, $R_{v a r}=0.8$. We simulated each scenario under different levels of temporal correlation between events, from $\rho=0$ to $\rho=0.8$. Finally, we constructed scenarios to explore the effects of external economic incentives, by varying the wages received per unit of time, from $W=1$ to $W=4$. Each simulation was conducted assuming households have different types of risk perception: a community composed of gain-seeking farmers and a community composed of loss-averse households. A gain-seeking community was constructed using parameters $\lambda=1$ and $a=1.5$ for gains and $\lambda=-0.5$ and $a=1$ for losses. A lossaverse community was composed using $\lambda=1$ and $a=0.5$ for gains and $\lambda=-1.5$ and $a=1$ for losses. We also simulated the model without considering risk attitude, using the Expected Utility formulation.

We generated 20 realizations for each combination of parameters, and we ran the model for a period of 100 time-steps. We recorded the community average number of fulfilled agreements (interactions of the form " $\mathrm{Cc}$ "); the number of households that decided to leave (strategy "Dd"); and the number of defections, represented by the number of unfulfilled agreements of the form "Cd." The name of the parameters and the range of values used are presented in Online Resources Table 1.

\section{Code availability}

The model was coded in Netlogo, version 5.2.1, and can be accessed at https://github.com/abaezacastro/Cooperation Chile, along with output files from the experiments and the scripts to rerun the analyses. The ODD protocol to describe agent- and individual-based models (Grimm et al. 2006) is included in the Online Resources, along with a detailed description of the decision-making processes using the framework MoHub (Schlüter et al. 2017) (Online Resources Fig. 4). The model will be archived in the library of CoMSES.

\section{Results}

\section{Effect of water scarcity}

When comparing the number of fulfilled agreements within a gradient of water availability, the results show that laborsharing contracts are formed more commonly in scenarios with high water abundance (Fig. 2a). More importantly, defections of the form $C d$ are more likely to be observed in environments that are neither extremely dry nor abundant but in the middle of the range of water availability (Fig. 3a). Under a high degree of scarcity, more households leave the community and, via mutual agreement, decide not to engage in labor-sharing, thereby increasing the number of interactions of the form $D d$ (Fig. 2a). At the other extreme, when water is abundant, most of the households decide to stay and most of the contracts are fulfilled. Overall, in communities coping with more stressful water conditions, more people move out of the community to work paying jobs (Online Resources Fig. 2). 

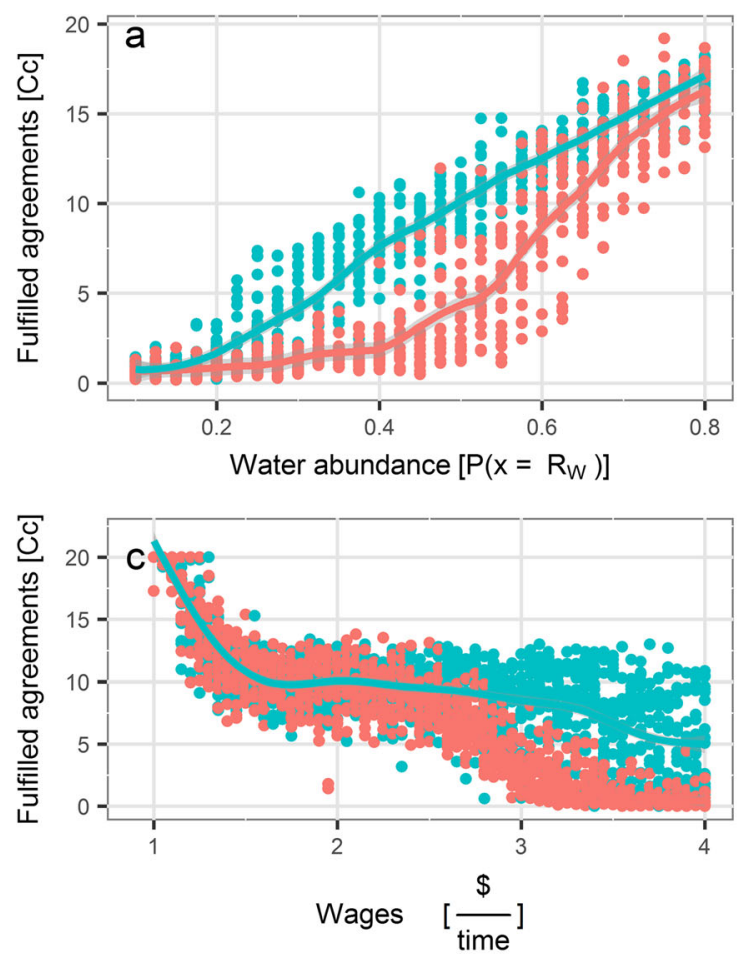

Fig. 2 Relationship between fulfilled labor-sharing agreements and scenarios of water availability, variability, wages, and temporal correlation of events. In each panel, a point in the $\mathrm{x}$, y plot represents results from a single simulation, with the $y$-axis showing the yearly average number of fulfilled agreements ("Cc") with respect to water abundance in a, water variability in $\mathbf{b}$, wages in $\mathbf{c}$, and temporal correlation between good and bad years in $\mathbf{d}$. a Shows that scenarios with more abundance of water can incentivize farmers to invest more time in helping each other. The colors red and blue display results assuming a community composed entirely of loss-averse and gainseeking farmers, respectively. b Shows the negative relationship
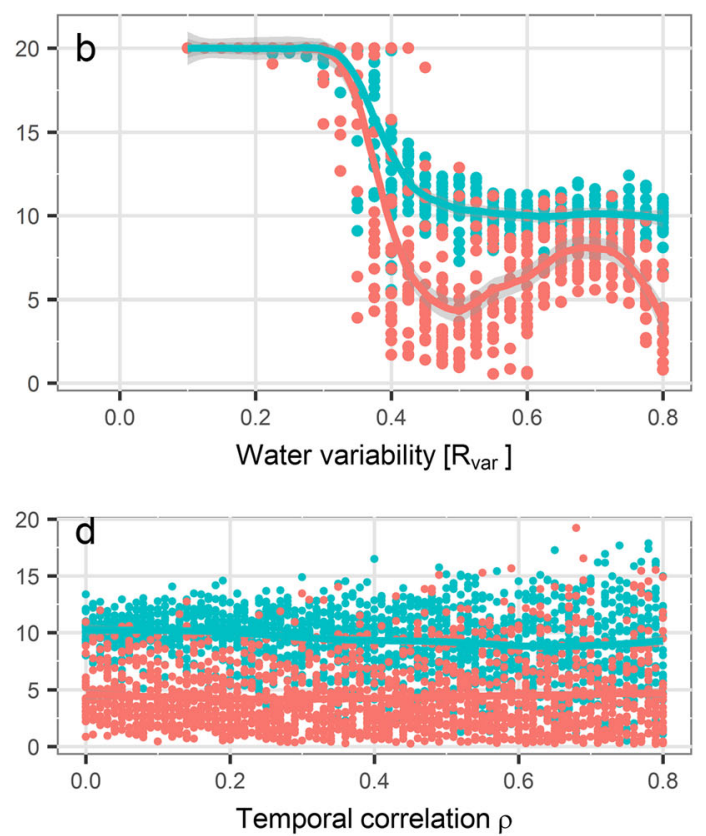

Risk behavior

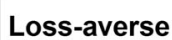

Gain-seeker

between the magnitude of the difference between good and bad years of water supply and the number of agreements that were fulfilled. c Shows how increasing off-farm wages can reduce the number of fulfilled agreements. Both water variability and wages influence the number of cooperative agreements in a non-linear way. $\mathbf{d}$ Displays the null effect of the temporal correlation between good and bad years. Overall, gainseeking farmers are more likely to engage in cooperative agreements than loss-averse farmers. The solid lines represent the results of fitting a local polynomial regression using the function "geom_smooth" in the software $R$

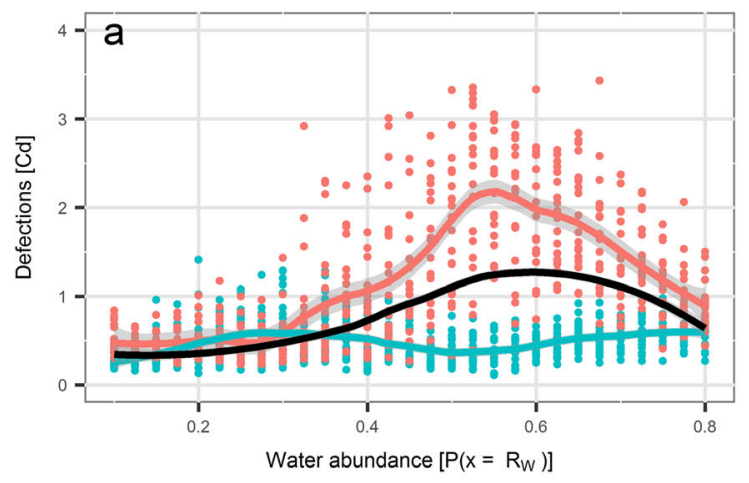

Risk behavior

Fig. 3 Relationship between defections and scenarios of water availability and water variability. The plots show the yearly average number of defections in the community. A defection is defined as an interaction that begins as an agreement to share labor but ends with one of the households leaving the community and not fulfilling the agreement strategy "Cd." In a, the number of defections are shown in a gradient of water abundance, which is represented by the probability of good years. In $\mathbf{b}$, defections are plotted against the magnitude of the variability

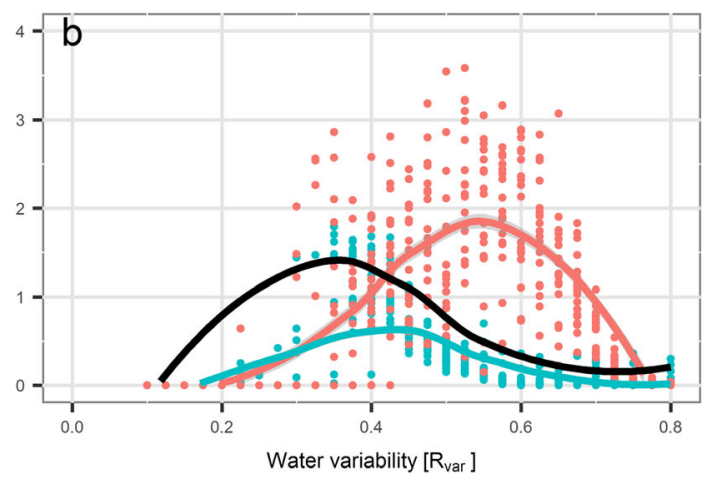

Loss-averse $=$ Gain-seeker

between good and bad years. Larger numbers of defections are observed in the middle range of variability and abundance and for scenarios with loss-averse farmers. The solid lines show the results of fitting a local polynomial regression, using the function "geom_smooth" in R. The black lines are the fitting of the local polynomial regression to the results obtained from the Expected Utility formulation. The full set of results from the EU formulation is presented in the Online Resources document (Online Resources Fig. 1) 
Significant differences are observed due to the risk behavior of the communities. Specifically, in communities composed of gain-seeking farmers, the number of fulfilled agreements increases linearly with the availability of water resources, whereas in scenarios with loss-averse farmers, this relationship, while still positive, is non-linear, suggesting that a large degree of water security is needed for farmers to start investing time in the community and helping others (Figs. 2 and 3). As shown in Fig. 3a, more defections of the form $\mathrm{Cd}$ are observed in scenarios where farmers are loss-averse. Scenarios with gain-seekers show less defections and less sensitivity to water availability.

Simulating the model using the Expected Utility formulation (Online Resources Fig. 1) generates fewer defections than simulations from risk-adverse communities, though there are a higher number of defections when compared to gain-seeker communities (Fig. 3b).

\section{Effect of water variability}

The magnitude of the fluctuation between good and bad years of agricultural productivity, due to water variability, also influences the social fabric of these communities. A negative and non-linear relationship is observed between the number of fulfilled agreements, $C c$, and the level of environmental variation (Fig. 2b). An abrupt decay in labor-sharing agreements is observed when the variability in water crosses a certain threshold $\left(R_{v a r}>0.2\right)$. This non-linear decay in the number of fulfilled agreements matches the rise of defections of the form $D c$, which correspond to interactions where an agreement was defined, but a final decision to leave was made (Fig. $3 b)$. The decay in fulfilled agreements and the rise of defections also coincide with a decline in trust (Fig. 4a). This waning of trust and, eventually, reputation among members of the

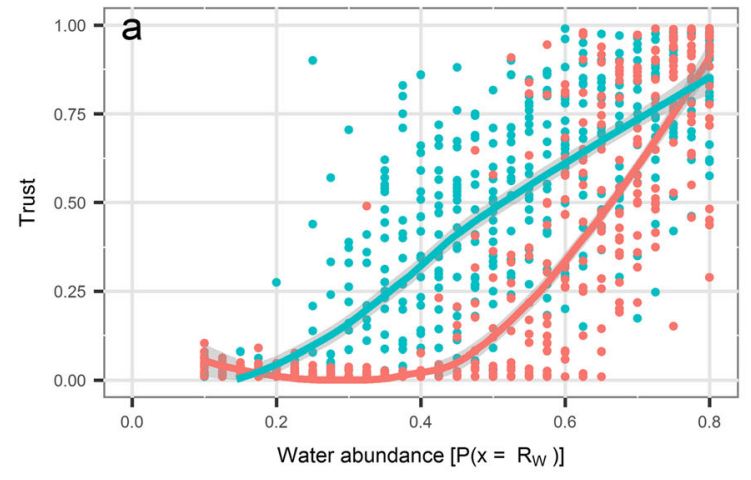

Risk behavior community reflects the tension that arises under environmental ambiguity and the need to cope with rapid environmental changes.

Similar to the effect of water abundance, the risk attitude among farmers also influenced the number of fulfilled agreements. Scenarios of communities composed of gain-seeker households generated more fulfilled agreements (Fig. 2b) and less defections (Fig.3b), when compared to loss-adverse communities. This occurred more often when the variability was extreme. It is in the mid-range of variability where simulations with gain-seekers differ the most from those with lossaverse farmers. Gain-seekers are willing to risk a major loss if the gain is larger and are more likely to stay in the community under intermediate levels of variability if they perceived that gains from staying in the community and cooperating are potentially greater than working outside the community. These decisions to stay allow them to accumulate larger amounts of wealth (Online Resources, Fig. 3a, b) compared to scenarios with loss-averse households. The influence of risk behavior starts to disappear under high levels of variability when the risk of a drought is extremely high, though the prospects of gain in a good year are also high (Fig. $3 \mathrm{~b}$ and Online Resources Fig. 1b).

Results from simulating the model using the expected utility formulation demonstrate that both models produce similar outcomes when farmers are loss-averse (Fig. 3a).

\section{External economic incentives}

Higher wages also result in a reduction of the time households spend in the community. As shown in Fig. 2c, strong nonlinearity emerges as a result of the feedback between social uncertainty, influenced by trust and reputation, and the external incentives that impact the decision to stay in the

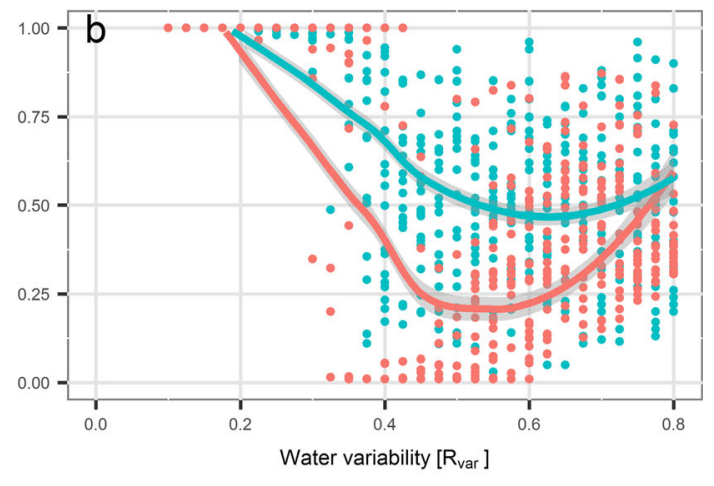

Loss-averse $=$ Gain-seeker

Fig. 4 Relationship between trust and scenarios of water availability and water variability. The figure in a shows the average level of trust in the community, in a range of scenarios of water availability represented by the probability of good years $\left(P\left(x_{t}=R_{W}\right)\right)$. b Illustrates how the level of trust decreases in a non-linear way, as the water variability, represented by the magnitude of the difference between a good and a bad year $\left(R_{v a r}\right)$, increases. Trust in others is higher in scenarios with gain-seeking farmers 
community despite the level of climatic variation and water availability. In a closed community without external markets, that is, when parameter $W=0,100 \%$ of the farmers engage in agriculture, including helping each other. As wages increase, a sharp decay in agreements is observed as more people decide to leave in pursuit of better outcomes (Fig. 2c and Online Resources Fig. 2).

\section{Temporal correlation between events and environmental uncertainty}

The temporal correlation between good and bad years of water availability did not influence the number of fulfilled agreements (Fig. 2d). Finally, when comparing simulations with complete uncertainty about the future availability of water versus scenarios in which households have knowledge of the true probability of an event, our results do not indicate significant differences.

\section{Discussion}

Rural communities in areas of transition between desert and forests are significantly affected by rapid climatic changes currently underway (Kepner et al. 2006; Huang et al. 2016). In particular, for the semi-desert region of Chile, significant changes in rainfall patterns, along with other socioenvironmental processes, have caused degradation (Leon 2007) and impacted the productivity of the land. Agricultural communities have adapted to these variable conditions by diversifying their activities, which often involves making the short-term decision of leaving the community in search of other opportunities. In this work, we show the possibility that these regional climate changes and short-term decision are exacerbating in the long-term the degradation of the social institutions and resource-based activities that have helped these communities to maintain cultural bonds and group identity.

We are not the first to suggest a connection between these regional climatic changes, the environmental degradation, and the decline of social relationships of these communities. Castro and Bahamondes, for instance, analyzed narratives from members of these communities about the effects that climate changes have had on their lives and on the social organizations that promote social bonds and cultural identity. They noted that many cultural traditions are disappearing in areas that suffer the most from water depletion, and they concluded that most of the activities and cooperative institutions that characterize the identity of these communities are currently only observed in the southernmost part of the region, where the land is more productive and water is more abundant (Castro and Bahamondes 1986).
Our study was limited by the lack of empirical data about the time households in these communities have invested in labor-sharing over time. In this context, the interpretation of our results must be considered with caution and should not be translated into policy interventions. They should be used as the basis for hypotheses of future empirical studies on institutional analysis. Specifically, our results suggest that risk attitude can have important consequences for maintaining the network of labor-sharing. In scenarios where gains were valued more heavily than avoiding losses, households were more willing to stay in the community and cooperate, despite social and environmental ambiguity. Maintaining social bonds and a perception of gain from these interactions can incentivize people to invest more time in their community to strengthen cultural bonds. Future studies should focus on understanding how the composition of these communities, in terms of age and gender, influences the perception of risk and the expectations for maintaining trustworthy relationships within the community and contributing to solving common problems. Empirical studies in rural communities of Africa, for instance, have shown that the perception of large losses in environments with scarcity can facilitate spiteful and competitive behavior (Prediger et al. 2013).

The model presented here therefore provides hypotheses that position within the same decision-making framework the economic decisions made by farmers, the behavioral factors behind them, and environmental variability and social uncertainty. By linking these processes in the context of regional environmental changes, our model illustrates the critical feedback between resource variability and social risk that leads to the erosion of trust and reputation and the subsequent degradation of the institutions that support cultural bonds. According to Mehta, a failure to recognize the inherent coupling between social and environmental factors that influence the structure of rural communities can lead to simplistic policy interventions that can reduce the adaptive capacity of these communities to maintain themselves in the face of environmental changes (Mehta et al. 1999). On the other hand, considering the preservation of these institutions over time and using strategies to cope with climate variability can provide new ways to combat desertification.

Our results also illustrate how external economic opportunities driven by global markets can influence the participation of farmers in cooperative institutions (Cárdenas et al. 2017). Access to other sources of income and more information can influence the perception that young people have of the prospect of living in rural areas, thereby incentivizing rural-urban emigration patterns. These global forces acting in concert with climate changes challenge the capacity of the system to maintain stable communities that can adapt to the changes in the environment (Janssen et al. 2007; Montaña et al. 2016). Policies that aim to achieve land restoration-economic incentives for reforestation, insurance schemes for climate- 
related disasters, or better prediction of rainfall—should consider the interactive nature of these socio-environmental processes in maintaining the cooperative institutions that shape the social fabric of these groups.

Cooperative institutions based on the exchange of other assets, such as land or water, have been observed in other dry regions of the world subjected to water scarcity and extreme variability. In pastoral communities of Australia, cooperative institutions known as "agistment" help rangers from distant communities share their land in order to reduce fluctuations in livestock size due to rainfall variability (McAllister et al. 2006). In Kenya, informal insurance schemes were created between pastoral communities to transfer animals among distant regions to reduce losses in years of rainfall scarcity (Dixit et al. 2012). In both cases, these insurance schemes are also maintained by trust and reputation. A critical difference between these strategies and the case of labor-sharing is the spatial scale at which these cooperative interactions are more likely to emerge in response to climatic variability. In the case of the insurance schemes in Kenya and the agistment contracts in Australia, the benefit of cooperation is obtained at large spatial scales, when the distance between the users of the resources (pastures) is large enough to generate sufficient spatial variability. In the case of labor-sharing, these decisions occur between closely located households that are similarly affected by climatic events. Both of these cooperative strategies (within and between communities) have been documented in Chilean communities (Alexander 2008), suggesting that they may be acting on and influencing the system at a more regional scale. Given the large area these communities cover and their strategic importance for reducing regional degradation (Leon 2007; Montaña et al. 2016), future research should aim to understand how these strategies, acting at multiple spatial and temporal scales, can lead to different socialeconomic and environmental outcomes.

\section{Conclusions}

Environmental changes in semi-desert regions of the world are impacting the prosperity of many rural communities that depend on the availability of seasonal pulses of water for agriculture and pastoralism. Farmers and pastoralists change their strategies to cope with prolonged droughts and extreme rainfall events. The agent-based model proposed in this work was developed to provide awareness and theoretical insight on how these environmental changes and strategies may have impacted the social fabric of these rural communities of Northern Chile and the ways they cooperate. The model shows that increase in rainfall variability and scarcity can negatively impact cooperation among farmers.

High dependency on weather patterns for production, social and environmental uncertainty, and strong external market forces are not just processes underway in Chile but in many other communities around the world. It is therefore critical for policy-makers, when designing and implementing policy instruments aimed at reducing environmental degradation, to consider the interaction between these processes and the perception and attitudes of people toward socio-environmental risk. An institutional analysis is needed to empirically validate these results and thus to understand how these regional environmental changes are influencing the way people invest resources in collective actions, public goods, and community building. Such analysis should provide valuable information for decision-makers when creating these policy instruments in this and other semi-arid regions. Furthermore, considering initiatives that can foster environmental restoration along with social cohesion and enhancement of collective institutions should provide more effective policies to combat desertification and land degradation in these fragile socio-ecological systems.

Acknowledgments We especially thank Ryan McAlister and the rest of the participants of the working group for their valuable comments during our meetings in Annapolis and Leipzig.

Funding information This research was supported by the National Socio-Environmental Synthesis Center (SESYNC) [Grant No. DBI1052875] through the Postdoctoral fellowship program to $\mathrm{AB}$ and the "Modeling Human Decision-making" working group with the German Center for Integrative Biodiversity Research (iDiv) to MJ. We also acknowledge the support from the Project MEGADAPT [NSF Grant No. 1414052].

Open Access This article is distributed under the terms of the Creative Commons Attribution 4.0 International License (http:// creativecommons.org/licenses/by/4.0/), which permits unrestricted use, distribution, and reproduction in any medium, provided you give appropriate credit to the original author(s) and the source, provide a link to the Creative Commons license, and indicate if changes were made.

\section{References}

Alexander WL (2008) Resiliency in hostile environments: a Comunidad Agrícola in Chile's Norte Chico. Associated University Presse, Cranbury

Anderies JM (2015) Understanding the dynamics of sustainable socialecological systems: human behavior, institutions, and regulatory feedback networks. Bull Math Biol 77:259-280. https://doi.org/10. 1007/s11538-014-0030-z

Cárdenas J-C, Janssen MA, Ale M et al (2017) Fragility of the provision of local public goods to private and collective risks. Proc Natl Acad Sci U S A 114:921-925. https://doi.org/10.1073/pnas.1614892114

Castro M, Bahamondes M (1986) Surgimiento y transformación del sistema comunitario: las comunidades agrícolas, IV Región, Chile. Ambient y Desarro 2:111-126

Caswell H (2001) Matrix population models. Wiley Online Library, New York City

Daily GC, Soderqvist T, Aniyar S et al (2000) The value of nature and the nature of value. Science 289(5478):395-396. https://doi.org/10. 1126/science.289.5478.395 
Debebe Z (2010) Child labor, agricultural shocks and labor sharing in rural Ethiopia. ISS Work Pap Ser Ser 491:1-60. https://EconPapers. repec.org/RePEc:ems:euriss: 18702

Dixit AK, Levin SA, Rubenstein DI (2012) Reciprocal insurance among Kenyan pastoralists. Theor Ecol 6:173-187. https://doi.org/10.1007/ s12080-012-0169-x

Downey SS (2010) Can properties of labor-exchange networks explain the resilience of Swidden agriculture? Ecol Soc 15(4). http://www. ecologyandsociety.org/vol15/iss4/art15/

Fiegenbaum A (1990) Prospect theory and the risk-return association. J Econ Behav Organ 14:187-203. https://doi.org/10.1016/01672681(90)90074-N

Gerichhausen M, Berkhout ED, Hamers HJM, Manyong VM (2009) A quantitative framework to analyse cooperation between rural households. Agric Syst 101:173-185. https://doi.org/10.1016/j.agsy.2009.05.005

Gilligan DO (2004) The economics of agricultural labor exchange with evidence from Indonesia. Dissertation, University of Maryland

Goldgeier JM, Tetlock PE (2001) Psychology and international relations theory. Ann Rev Polit Sci 4:67-92. https://doi.org/10.1146/annurev. polisci.4.1.67

Grimm V, Berger U, Bastiansen F et al (2006) A standard protocol for describing individual-based and agent-based models. Ecol Model 198:115-126. https://doi.org/10.1016/j.ecolmodel.2006.04.023

Hames R (1987) Garden labor exchange among the Ye'kwana. Ethol Sociobiol 8:259-284. https://doi.org/10.1016/0162-3095(87) 90028-8

Hastie R, Dawes R (2010) Rational choice in an uncertain world: the psychology of judgment and decision making. SAGE, Los Angeles

Hearne R, Donoso G (2014) Water markets in Chile: are they meeting needs? In: Water markets for the 21 st century. Springer, New York

Herman JD, Zeff HB, Reed PM, Characklis GW (2014) Beyond optimality: multistakeholder robustness tradeoffs for regional water portfolio planning under deep uncertainty. Water Resour Res 50:76927713. https://doi.org/10.1002/2014WR015338

Huang J, Ji M, Xie Y et al (2016) Global semi-arid climate change over last 60 years. Clim Dyn 46:1131-1150. https://doi.org/10.1007/ s00382-015-2636-8

Janssen MA (2008) Evolution of cooperation in a one-shot prisoner's dilemma based on recognition of trustworthy and untrustworthy agents. J Econ Behav Organ 65:458-471. https://doi.org/10.1016/j. jebo.2006.02.004

Janssen MA, Anderies JM, Ostrom E (2007) Robustness of socialecological systems to spatial and temporal variability. Soc Nat Resour 20:307-322. https://doi.org/10.1080/08941920601161320

Kahneman D, Tversky A (1979) Prospect theory: an analysis of decision under risk. J Econ Soc 47:263-292. https://doi.org/10.2307/ 1914185

Kepner WG, Rubio JL, Mouat DA, Pedrazzini F (2006) Desertification in the Mediterranean region. A Security Issue. Kluwer Academic Publishers, Dordrecht

Leon A (2007) Household vulnerability to drought and ecosystem degradation in northern Chile. Universidad de Chile, Dissertation

McAllister RRJ, Gordon IJ, Janssen MA, Abel N (2006) Pastoralists' responses to variation of rangeland resources in time and space.
Ecol Appl 16:572-583. https://doi.org/10.1890/1051-0761(2006) 016[0572:PRTVOR]2.0.CO;2

Mehta L, Leach M, Newell P, et al (1999) Exploring understandings of institutions and uncertainty: new directions in natural resource management.

Minetti JL, Vargas WM, Poblete AG et al (2003) Non-linear trends and low frequency oscillations in annual precipitation over Argentina and Chile, 1931-1999. Atmósfera 16:119-135

MBNGC (2017) Oficina Técnica de Comunidades Agrícolas. Ministerio de Bienes Nacionales. http://www.comunidadesagricolas.cl/. Accessed 11 Feb 2017

Montaña E, Diaz HP, Hurlbert M (2016) Development, local livelihoods, and vulnerabilities to global environmental change in the south American dry Andes. Reg Environ Chang 16:2215-2228. https:// doi.org/10.1007/s10113-015-0888-9

Mui, L., Mohtashemi, M. and Halberstadt, A., (2002) A computational model of trust and reputation. In system sciences, 2002. HICSS. Proceedings of the 35th annual Hawaii international conference on (pp. 2431-2439). IEEE.

Podestá G, Bert F, Rajagopalan B et al (2009) Decadal climate variability in the Argentine Pampas: regional impacts of plausible climate scenarios on agricultural systems. Clim Res 40:199-210. https://doi. org/10.3354/cr00807

Prediger S, Vollan B, Herrmann B (2013) Resource scarcity, spite and cooperation

Reynolds JF, Smith DMS, Lambin EF et al (2007) Global desertification: building a science for dryland development. Science 316:847-851. https://doi.org/10.1126/science.1131634

Rocha Pérez R (2006) Las comunidades agrícolas del semiárido chileno: una forma particular de campesinado. Boletín de Geografía de Chile:21-32

Salas S, Jiménez E, Montaña E et al (2012) Vulnerability to climate change, challenges for adaptation in the Elqui and Mendoza basins. Salas, Jiménez \& Bugueño, La Serena

Schlüter M, Baeza A, Dressler G et al (2017) A framework for mapping and comparing behavioural theories in models of social-ecological systems. Ecol Econ 131:21-35. https://doi.org/10.1016/j.ecolecon. 2016.08.008

Silva E, Sanchez R, Herrera M (1978) Estudio de las Comunidades Agricolas IV Region. Santiago

Souvignet M, Gaese H, Ribbe L et al (2010) Statistical downscaling of precipitation and temperature in north-central Chile: an assessment of possible climate change impacts in an arid Andean watershed. Hydrol Sci J 55:41-57. https://doi.org/10.1080/02626660903526045

Suehara T (2006) Labor exchange systems in Japan and DR Congo: similarities and differences.

Sydnor J (2010) (Over)insuring modest risks. Am Econ J Appl Econ 2: 177-199. https://doi.org/10.1257/app.2.4.177

Wakker PP (2010) Prospect theory: for risk and ambiguity. Cambridge University Press, Cambridge

Waring TM (2006) Cooperation dynamics in a multiethnic society: a case study from Tamil Nadu. Curr Anthropol 53:642-649. https://doi. org/10.1086/666942 